\title{
Institutionalizing Ethics: Historical Debates surrounding IEEE's 1974 Code of Ethics
}

Dr. Xiaofeng Tang, Penn State University

Xiaofeng Tang is a postdoctoral fellow in engineering ethics at Penn State University. He received his $\mathrm{PhD}$ in Science and Technology Studies from Rensselaer Polytechnic Institute.

\section{Dr. Dean Nieusma, Rensselaer Polytechnic Institute}

Dean Nieusma is Associate Professor in Science and Technology Studies and Director of the Programs in Design and Innovation at Rensselaer. 


\title{
Institutionalizing Ethics: Historical Debates Surrounding IEEE's 1974 Code of Ethics
}

\author{
Contribution to the special session "Non-canonical Canons in Engineering Ethics"
}

\section{Introduction}

Consider this case. Three engineers work for a governmental department which oversees the construction of a large-scale public transit system. Having participated in the project for a number of years, they find serious problems in the management and deployment of the engineering work, which have led to a waste of public funds and pose a threat to the safety of commuters. After reporting their concerns to their direct managers, they receive only vague responses and witness no action to address the problems. Should the engineers reach out to a higher level of management and/or speak out publicly about the problems and hazards associated with the project? The answer to this question might seem obvious: Particularly because public safety is at issue, the engineers should continue reporting the problems up the chain until they are properly addressed. Not to do so would be a violation of the codes of ethics of several professional engineering societies. ${ }^{1}$ Cases similar to this one have been assigned to students in numerous engineering ethics classes over recent decades, and the appropriate response to the ethical question is often guided by direct reference to professional ethics codes.

The ethics case above draws on a real-world situation from the 1970s. Three engineers who worked on the Bay Area Rapid Transit (BART) project, Holger Hjortsvang, Max Blankenzee, and Robert Bruder, discovered severe problems with the project's Automated Train Control System. After their initial reports documenting the problems were dismissed by their supervisors, the three engineers contacted a member of the BART Board of Directors to express their concerns. Consequentially, the problems were made public in a press conference. Shortly afterwards, the three engineers were fired by BART management with no reason given. Despite acting in accordance with widely acknowledged principles of professional ethics around protecting the safety of the public, as this case illustrates, such actions may result in retaliation by employers, including dismissal. Fortunately, the BART engineers received support from their professional engineering society, the Institute of Electrical and Electronics Engineers (IEEE). In 1975, IEEE provided an amicus curiae brief in support of the three engineers' suit against BART management for wrongful discharge. Shortly after the brief, "BART offered the three engineers an out-of-court settlement," which the engineers accepted. ${ }^{2}$ In 1978, Blankenzee, Bruder, and Hjortsvang were honored with the first IEEE Committee on Social Implications of Technology Award for Outstanding Service in the Public Interest. ${ }^{3}$

Told this way, the BART engineers' story paints a matter-of-fact picture of engineers speaking truth to power and their professional engineering society supporting, even honoring, their efforts 
to uphold their professional code of ethics. However, a careful look at the history of IEEE's involvement in the BART case reveals not a straightforward story but some curious exceptions. Exception One: The IEEE "Code of Ethics for Engineers" had not existed when the three engineers were fired in 1972. In fact, it was the BART case that sparked discussions of professional ethics within IEEE and inspired the eventual adoption of its first "Code of Ethics for Engineers" in 1974. Exception Two: The BART case was the only occasion in which the IEEE filed an amicus curiae brief in support of any of its members in court. ${ }^{4}$ Certainly other IEEE members have faced managerial reprisal for upholding various canons of their Code of Ethics following 1974, yet legal support from IEEE appears not to be forthcoming. Exception Three: The initiative to support an IEEE Award for Outstanding Service in the Public Interest met a divided response within IEEE. In the end, the award was not approved as a standing IEEE "technical field award" but was instead determined to be given only on a case-by-case basis, subject to the approval of the IEEE Executive Board. This ad-hoc standing suggests both discomfort within IEEE leadership over the purpose of the award as well as desire by that leadership to maintain direct control over any granting of the award.

These exceptions suggest that the BART case was not a straightforward illustration of how professional codes of ethics typically work in practice. Beyond catalyzing the creation of the IEEE Code of Ethics, the BART case also demonstrated the tensions that arise between professional ethics codes as formal guides to practice and the reality of organizational decision making, where employers determine appropriate courses of action even when involving questionable engineering practices. The BART case tested the extent to which the IEEE was willing to support its members' job-related practices when they expressly contradicted the will of their employers. Such contextual factors provide important insight on the role of codes of ethics in guiding real-world engineering practice, particularly by highlighting important gaps between what is portrayed by the codes and professional societies' appetite for controversy arising from actual ethical dilemmas.

This paper examines the historical context around the establishment of IEEE's first "Code of Ethics for Engineers," focusing specifically on the early history of the IEEE Committee on Social Implications of Technology (CSIT) and the advocacy activities of one of its co-founders, Stephen H. Unger. CSIT and Unger played a crucial role in the creation and adoption of the 1974 IEEE "Code of Ethics for Engineers" and in urging IEEE to support engineers whose adherence to the Code of Ethics exposed their careers to risk. Through revealing the historical contestations over enacting and enforcing a code of professional ethics within IEEE, we attempt to bring to light some of the uncertainties, disagreements, and compromises that lie hidden behind the projection of an authoritative "code": What IEEE sanctions as ethical engineering practice is by no means unilateral, and in important respects, the outcome of the BART case may be understood less as following the rule and more as an exception. After documenting the historical circumstances surrounding the 1974 Code, we discuss the importance of understanding the 
contexts behind ethics codes and the implications of such a contextual understanding for engineering ethics education.

The historical narrative presented in this paper stems from a study of the institutional history of another engineering organization in the 1970s: the Committee for Social Responsibility in Engineering (CSRE). In the summer of 2011, the authors of this paper conducted archival research of CSRE's publication, Spark Magazine. Although CSRE stood as a dissident group within the engineering establishment throughout its existence, our research showed that some of CSRE's core members were also playing important roles in the mainstream professional engineering societies, such as IEEE. For example, Unger - an active contributor to Spark Magazine - also helped organize CSIT within IEEE and published regularly in the IEEE CSIT Newsletter. Following this thread, we located original copies of the IEEE CSIT Newsletter in Syracuse University Libraries. One of the authors travelled there, read, and scanned copies of the Newsletter. Both authors then read through these copies, focusing on articles authored by Unger as well as those describing the activities of CSIT. Hence, this paper draws exclusively from published data surrounding Unger's and CSIT's involvement with creating and revising the IEEE Code. We note that after our archival research, electronic versions of all copies of the CSIT Newsletter were released by IEEE Xplore Digital Library.

\section{Seeking to Depart from Tradition: The Founding of CSIT}

In a critical review of American engineering profession's intellectual history, philosopher Carl Mitcham suggests the major paradigms of engineering ethics before the end of the World War II stressed: 1) engineers' loyalty to their employers and clients; and 2) the efficiency of engineering work. ${ }^{5}$ As science and technology boomed over more than a decade following the end of the war, many engineers became sensitized to the complex role modern technoscience played in postwar society and, hence, advocated more stringent professional oversight of technoscientific developments. As engineering historian Matthew Wisnioski notes, "environmental degradation, the Vietnam War, and a host of socio-technical concerns led reformers to pressure their profession to honor its social responsibilities." ${ }^{6}$ In 1971, a group of engineers who were determined to "challenge the present orientation of engineering and to explore ways in which engineering skills can be used to solve the obvious and growing ills of our society" came together to form the Committee for Social Responsibility in Engineering. ${ }^{7}$ Many of CSRE's members were electrical engineers and also members of IEEE. Attempting to bring debates around important societal issues into the major professional engineering societies, CSRE members initiated a petition to form a Professional Group within IEEE on the Social Implications of Technology. ${ }^{8}$ The IEEE Executive Committee denied the petition, but agreed to establish an Ad Hoc Committee on Social Implications of Technology (CSIT). The Ad Hoc Committee was placed under the administration of the IEEE Technical Activities Board (TAB). ${ }^{9}$ 
In December 1972, CSIT published the first issue of the IEEE CSIT Newsletter, whose cover listed the new Committee's purposes:

1. Develop means to encourage and support professional and social responsibility in the practice of engineering.

2. Promote sensitivity to and understanding of the interaction between technology and society.

3. Foster study, discussion and appropriate action involving IEEE members and others.

4. Promote the conception of means and implement programs for predicting and evaluating the impact of technology on society.

5. Take appropriate action to implement programs. ${ }^{10}$

In a short editorial, the Newsletter editor explained the relevance and urgency of debating the repercussions of scientists' and engineers' decisions. The editor committed to "providing a forum in which all IEEE members, as well as other experts in non-technical fields such as law, economics and the social sciences, may express their thoughts concerning the social, ethical, medical, legal and moral implications of the present course of the engineering discipline." 11 Such a move, the editor acknowledged, "may be a new departure from the traditional role of a technical organization." 12

During its first five years, the IEEE CSIT Newsletter published unequivocal views on a variety of important topics concerning IEEE specifically, professional engineering organizations generally, and the appropriate roles of technology within broader society, including questions around nuclear power, product safety standards, military technologies, system engineering, and social problem solving. ${ }^{13}$ Some of these discussions had significant and lasting impacts on IEEE, not least concerning institutional recognition of the importance of professional ethics. CSIT members not only promoted a strong code of professional ethics be adopted by IEEE, but also advocated formal structures to protect and support engineers who acted in accordance with their professional codes of ethics. Unger, one of CSIT's co-founders, played a central role in these efforts.

\section{The Dilemma for Ethical Engineers and Unger's Solutions}

Engineering professor Stephen H. Unger spent most of his career at Columbia University, where he taught computer science and electrical engineering. Unger participated in the founding of CSIT and later chaired the Committee. ${ }^{14}$ In 1973, Unger first reported to CSIT the three engineers who spoke out about the problems in the BART project and the cost they paid for their efforts to protect the public's interest. ${ }^{15}$ Unger noted that although the three engineers' report led to investigations by the California Society of Professional Engineers (CSPE) and the California State Legislature, which confirmed the problems they identified with the BART project, neither CSPE nor the State Legislature even mentioned, not least addressed, the wrongful firing of the three engineers. ${ }^{16}$ Unger suggested the predicament facing the BART engineers was not unique but a fairly common dilemma confronting engineers as employees, who are "forced to choose 
between compromising their ethics or seriously jeopardizing their careers." ${ }^{17}$ In Unger's assessment, engineers ought to have the right to practice their professional service according to their ethical standards, but the opposition of employers or clients might significantly compromise this right, at least for employed professionals and those "who have a relatively small clientele.", 18

In the next issue of the IEEE CSIT Newsletter following the reporting of the BART incident, Unger published two articles in which he offered potential solutions to the dilemma. Given that individual engineers have little negotiating power against their employers or clients, Unger argued it is the obligation of professional engineering societies to change the engineering environment so as to "make it possible for the employee engineer to operate as a responsible professional without being subjected to major risks of unfair employer retaliation." ${ }^{19}$ In particular, Unger suggested two means for professional engineering societies to fulfill this obligation. First, he proposed adopting a code of engineering ethics in order to remind engineers that "they have obligations beyond simple commercial contracts with their employers (or, in some cases clients)." ${ }^{20}$ However, Unger was not naive in expecting that ethical outcomes would be achieved by individual engineers voluntarily risking their employment. Instead, he advocated professional engineering societies provide institutional protection of employees' rights to pursue ethical practices. Specifically, Unger proposed the establishment of an ombudsman's office within IEEE, which would handle complaints of problematic management behaviors, including "alleged violations of the public interest.", 1

IEEE was surprisingly late in implementing its own code of ethics compared with similar societies like American Society of Mechanical Engineers (ASME) and American Society of Civil Engineers (ASCE), both of which adopted their codes of ethics in 1914. However, this state of affairs resulted partly from a historical contingency. The predecessor of IEEE, the American Institute of Electrical Engineers (AIEE), adopted its code of ethics in 1912. ${ }^{22}$ In 1963, AIEE merged with the Institute of Radio Engineers, resulting in the creation of IEEE. But it appears AIEE's code did not survive the merger, and IEEE did not pursue development of an ethics code until the early 1970s (the period covered by this paper). What happened in the intervening years, and in particular the formation and orientation of IEEE's leadership structure, is beyond the scope of our analysis, but is worthy of future research.

Unger's proposals to establish a code of ethics and to create institutional structures to support ethical engineers were endorsed by CSIT. Several authors echoed Unger's opinions in the following issues of the IEEE CSIT Newsletter. Walter L. Elden, an engineer working at Martin Marietta until resigning under coercion in 1974, discussed the dilemma facing employed engineers and called for a code of ethics to ensure ethical practice. ${ }^{23}$ Roy W. Anderson, the Chairman of CSPE's Transportation Safety Committee, recalled his frustrated efforts to support the fired BART engineers. According to Anderson, instead of advocating for their members who acted in the public interest, even CSPE's leaders attempted to censure the local CSPE chapter, which actively sought to investigate the unjust firing by the BART management. In light of this experience, Anderson concluded: "I know of no professional engineering organization that 
actively encourages their members to register complaints based on ethics and then follows through with investigation and action."24

Despite persistent advocacy on the part of CSIT, the IEEE "Code of Ethics for Engineers," as first adopted in 1974, deviated significantly from Unger's proposed emphasis on professional engineers' obligation to the public interest. Efforts to establish effective institutional structures within the IEEE to support and enforce its Code of Ethics also met with prolonged struggles.

\section{The Missing Canon}

In February 1975, the "IEEE Code of Ethics for Engineers" ("the IEEE Code" hereafter) was published in Spectrum, the official magazine of IEEE. This code is reproduced verbatim in Figure 1, below. In a short paragraph introducing the Code, the President of IEEE, Arthur P. Stern, explained that the published code was adopted by IEEE's Board of Directors on December 4, 1974. Stern also acknowledged that in the creation of the code, "expert views were obtained from the Committee on Social Implications of Technology and many other IEEE organizational units." ${ }^{, 25}$ Despite this nod to CSIT's input, the published code differs in important ways from the original code drafted by Unger and his CSIT colleagues. At a CSIT forum in March 1973, Unger delivered a paper in which he proposed 17 points to form a code of ethics for engineers. Unger's draft code was circulated to the CSIT Working Group on Ethics. After comments and revision by the Working Group members, a code consisting of 18 canons ("the Unger Code" hereafter) was recommended to replace the code of the Engineers Council for Professional Development (ECPD). ${ }^{26}$ The Unger Code is reproduced in Figure 2, below. A comparison of the IEEE Code (Figure 1) and the Unger Code (Figure 2) indicates the authors' differing views on priorities within engineering ethics and, in particular, on the scope of engineers' responsibility to the public.

A close reading of these two codes of ethics reveals differential emphasis, particularly surrounding engineers' responsibilities to the public. The "Preamble" of the IEEE Code states engineers should "merit the confidence of colleagues, employers, clients and the public" (emphasis added). ${ }^{27}$ In contrast, the Unger Code has as a fundamental principle that the engineer should serve "with fidelity the public, his employer and his clients" (emphasis added). ${ }^{28}$ If this slight difference in phrasing is accidental, the structure and ordering of the canons themselves in each of the two codes further illustrates their respective priority. The 19 canons in the IEEE Code are organized under four "articles." Article I contains five canons that require "diligence, creativity, and productivity." 29 These canons taken together can be understood as requirements for engineers to be "credible technical experts." Similarly, Article II and Article III can be understood in general as requirements for engineers to be "supportive colleagues" and "loyal employees." Engineers' responsibilities to the public, or the requirements of engineers as "public servants," only appear explicitly in the three canons under Article IV, which require engineers to 


\section{IEEE Code of Ethics for Engineers}

\section{PREAMBLE}

Engineers affect the quality of life for all people in our complex technological society. In the pursuit of their profession, therefore, it is vital that engineers conduct their work in an ethical manner so that they merit the confidence of colleagues, employers, clients and the public. The IEEE Code of Ethics is a standard of professional conduct for engineers.

\section{ARTICLE I}

Engineers shall maintain high standards of diligence, creativity and productivity, and shall:

1. Accept responsibility for their actions;

2. Be honest and realistic in stating claims or estimates from available data;

3. Undertake engineering tasks and accept responsibility only if qualified by training or experience, or after full disclosure to their employers or clients of pertinent qualifications;

4. Maintain their professional skills at the level of the state of the art, and recognize the importance of current events in their work;

5. Advance the integrity and prestige of the engineering profession by practicing in a dignified manner and for adequate compensation.

Engineers shall, in their work:

1. Treat fairly all colleagues and co-workers, regardless of race, sex, age or national origin;

2. Report, publish and disseminate freely information to others, subject to legal and proprietary restraints;

3. Encourage colleagues and co-workers to act in accord with this Code and support them when they do so;

4. Seek, accept and offer honest criticism of work, and properly credit the contributions of others;

5. Support and participate in the activities of their professional societies;

6. Assist colleagues and co-workers in their professional development.

\section{ARTICLE III}

Engineers shall, in their relations with employers and clients:

1. Act as faithful agents or trustees for their employers or clients in professional and business matters, provided such actions conform with other parts of this Code;

2. Keep information on the business affairs or technical processes of an employer or client in confidence while employed, and later, until such information is properly released, provided such actions conform with other parts of this Code;

3. Inform their employers, clients, professional societies or public agencies or private agencies of which they are members or to which they may make presentations, of any circumstance that could lead to a conflict of interest;

4. Neither give nor accept, directly or indirectly, any gift, payment or service of more than nominal value to or from those having business relationships with their employers or clients;

5. Assist and advise their employer or clients in anticipating the possible consequences, direct and indirect, immediate or remote, of the projects, work or plans of which they have knowledge.

\section{ARTICLE IV}

Engineers shall, in fulfilling their responsibilities to the community:

1. Protect the safety, health and welfare of the public and speak out against abuses in these areas affecting the public interest;

2. Contribute professional advice, as appropriate, to civic, charitable or other non-profit organizations;

3. Seek to extend public knowledge and appreciation of the engineering profession and its achievements.

Figure 1. The 1974 IEEE Code of Ethics for Engineers ${ }^{30}$

protect the public welfare, contribute professional skills to civic organizations, and extend public knowledge of engineering. The Unger Code contains 18 "fundamental canons of ethics," the first four of which address public welfare, health, and safety; the broader impacts of engineering projects; and contributing professional service to public causes. ${ }^{31}$ At least three of these canons 


\section{The CSIT Working Group Proposal (the "Unger Code")}

Fundamental Principles

The Engineer upholds and advances the honor and dignity of the engineering profession by:

I. Using his knowledge and skill for the advancement, never the detriment, of human welfare;

II. Being honest and impartial, and serving with fidelity the public, his employer and his clients;

III. Striving to increase the competence and prestige of the engineering profession.

Fundamental Canons of Ethics

1. The Engineer has proper regard for the safety, health and welfare of the public in the performance of his professional duties, and he will regard his duty to the public welfare as paramount by notifying the proper authority of any observed conditions which endanger public safety and health.

2. The Engineer does whatever is practicable to assure the safety and reliability of products for which he is responsible and accepts responsibility for personal errors.

3. The Engineer makes a reasonable effort to inform himself as to the possible consequences, direct and indirect, immediate and remote, of projects he is working on.

4. The Engineer contributes his professional skills to worthy public causes.

5. The Engineer does not disclose confidential information concerning the business affairs or technical processes of any present or former client or employer without his consent, except in unusual circumstances where FP-1, FC-1, or FC-2 above may call for special action in the public interest.

6. The Engineer does not associate with or allow the use of his name by an enterprise of questionable character, nor does he become professionally associated with those who do not conform to ethical practices, or with persons not professionally qualified to render the services for which the association is intended.

7. The Engineer encourages colleagues and co-workers to act ethically in their work and supports them when they do so.

8. The Engineer does not undertake engineering assignments for which he will be responsible when unqualified by training or experience (without so notifying clients or employer).

9. The Engineer accepts compensation, financial or otherwise, from only one interested party for the same service, or for services pertaining to the same work, unless there is full disclosure to and consent of all interested parties.

10. The Engineer cooperates in extending the effectiveness of the profession by interchanging information and experience with other engineers, junior colleagues, technicians, and students, and he endeavors to provide opportunities for the professional development and advancement of those under his supervision. The Engineer does not discriminate against colleagues or co-workers on such irrelevant grounds as race, religion, or sex.

11. The Engineer seeks, accepts, and offers honest criticism of his and others' work.

12. The Engineer does not injure, maliciously or falsely, directly or indirectly, the professional reputation, prospects, practice or employment of another engineer, nor does he indiscriminately criticize another engineer's work.

13. The Engineer endeavors to extend public knowledge, and to promote understanding of the contributions and achievements of engineering and the alternatives offered by modern technology.

14. The Engineer gives credit for work to those to whom credit is due, and recognizes the proprietary interests of others.

15. The Engineer advertises his work or merit in a dignified manner, and avoids conduct or practice likely to discredit or unfavorably reflect upon the dignity or honor of the profession.

16. The Engineer is guided in all his professional relations by the highest standards of integrity, and acts in professional matters for each client or employer as a faithful agent and trustee.

17. The Engineer supports the professional and technical societies of his discipline.

18. The Engineer upholds the principle of appropriate and adequate compensation for those engaged in engineering.

Figure 2. CSIT'S Proposed Revision to the ECPD Code of Ethics ${ }^{32}$

explicitly address engineers' ethical responsibilities to the public. ${ }^{33}$ Moreover, Canon 1 in the Unger Code clearly states engineers' duty to the public welfare is "paramount." "T4 The language of "paramount" responsibilities was not adopted in the 1974 IEEE Code or its following iterations. 
Besides differently prioritizing responsibility to the public, the IEEE Code and the Unger Code also present differently the scope of engineers' public responsibilities. Article IV, Canon 1 in the IEEE Code requires engineers to "protect the safety, health and welfare of the public and speak out against abuses in these areas affecting the public interest.", The language of "protecting" and discouraging "abuses" relies upon a philosophy of "avoiding harm": It requires engineers not to produce negative impact on the public, and to speak out if negative impact occurs. Unger and his colleague in CSIT went beyond the philosophy of avoiding harm by requiring engineers to produce positive effects for humanity through their work. The first fundamental principle in the Unger Code demands engineers to use their knowledge and skill "for the advancement, never the detriment, of human welfare." 36 This principle suggests engineering work that is solely for the profit of employers and clients, even though innocuous to others, might contradict engineers' ethical responsibilities. When it comes to the safety and reliability of engineering work, the Unger Code does not limit engineers' responsibility to "speaking out" against abuses; more affirmative actions are required. Canon 2 in the Unger Code specifies engineers should do "whatever is practicable to assure the safety and reliability of products." 37

Unfortunately, our archive research did not shed much light on the processes and procedures through which the code originally proposed by Unger and CSIT was changed by IEEE's leadership and finalized into the IEEE Code. However, Unger and his colleagues in CSIT were acutely aware of the inadequacy — at least in their assessment — of the code adopted by IEEE in 1974. In 1976, Unger proposed a revision to the IEEE Code (Figure 3), adopting the structure of the IEEE Code but more strongly emphasizing engineers' public responsibilities. The primary change required, as Unger explained it, was "an added emphasis on the engineer's responsibility to society." 38 This change was implemented primarily through reordering the canons. Article I in the "Proposed Revision" reiterates "engineers shall regard their responsibility to society as paramount," and all five canons under Article I describe engineers' responsibilities to the public. $^{39}$

Conspicuous in this proposed revision is the return of the expectation of net-positive social impact. Article I, Canon 2 states engineers shall: "Endeavor to direct their professional skills toward ends they deem, on balance, to be of positive value to humanity; declining to use those skills for purposes they consider, on balance, to conflict with their moral values." 40 Unger called attention to this canon in his explanation of the proposed revision: "The intent here is to promulgate the idea that the engineer should try to make the product of his work beneficial to mankind." 41 The term "on balance" was added because Unger realized engineering projects often have multiple impacts and different people might disagree over what is good. However, Unger believed it to be improper to allow the uncertainties in engineering outcomes and the value disagreements to excuse engineers from making judgments: "the point is that a professional does make such assessments rather than blindly following orders." "42 


\section{Proposed Revision of IEEE Code of Ethics for Engineers}

Preamble

Engineers affect the quality of life for all people in our complex, technological society. It is therefore vital that they pursue their profession in an ethical manner so as to merit the confidence of colleagues, employers, clients and the public. This IEEE Code of Ethics is a standard of professional conduct for engineers.

Article I Engineers shall regard their responsibility to society as paramount and shall:

1. Inform themselves and others, as appropriate, of the consequences, direct or indirect, immediate and remote of the projects they are involved in;

2. Endeavor to direct their professional skills toward ends they deem, on balance, to be of positive value to humanity; declining to use those skills for purposes they consider, on balance, to conflict with their moral values.

3. Protect the safety, health and welfare of the public; speaking out against abuses of the public interest that they may encounter in the course of professional activities in whatever manner is best calculated to lead to a remedy;

4. Help inform the public about technological developments and the alternatives they make feasible;

5. Contribute professional advice, as appropriate, to worthy non-profit organizations.

Article II Engineers shall practice their profession in a dignified, responsible manner and shall:

1. Keep their professional skills up to date and be aware of current events that may affect or be affected by their work;

2. Be honest and realistic in stating claims and estimates; never falsifying data;

3. Accurately describe their qualifications for proposed engineering assignments.

Article III Engineers shall, in their relations with employers and clients:

1. Act as faithful agents or trustees for their employers and clients in business or professional matters, provided such actions conform with other parts of this code;

2. Keep information on the business affairs or technical processes of an employer or client in confidence while employed and later, until such information is properly released, provided such actions conform with other parts of this code;

3. Inform their employers, clients, professional societies or agencies, public or private, of which they are members or to which they may make presentations, of any circumstance that could lead to a conflict of interest;

4. Neither give nor accept, directly or indirectly, any gift, payment or service of more than nominal value to or from those having business relationships with their employers or clients.

Article IV Engineers shall, in relations with colleagues and co-workers:

1. Seek, accept and offer honest criticism of work, and properly credit the contributions of others;

2. Assist colleagues and co-workers in their professional development and treat them fairly regardless of race, religion, sex, age or national origin;

3. Encourage colleagues and co-workers to act in accord with this Code and support them when they do so;

4. Report, publish and disseminate information freely, subject to legal and proprietary restraints, provided such actions conform with other parts of this Code;

5. Promote Safety in work situations.

\section{Figure 3. Unger's Proposed Revision to the IEEE Code of Ethics for Engineers ${ }^{43}$}

In a meeting following the publication of Unger's proposed revision, CSIT formally endorsed the revision and urged the IEEE Board to adopt it. However, IEEE made no revisions to its code of ethics until 1979, and then the revision was driven by an entirely different issue involving the changing nature of the technical workforce. ${ }^{44}$ To date, a canon that compels engineers to produce positive social impacts via their work has not been included within any version of the IEEE Code. 


\section{Implementing the Code}

In his first article that introduces the idea of implementing a code of ethics to readers of the IEEE CSIT Newsletter, Unger pondered "whether [the code] would be useful beyond having mild educational effect." 45 Unger sensibly realized that, without effective institutional support, engineers' faithful adherence to the code might end up "getting them into trouble with their employers." 46 In "Ethics for Engineers: A Code and Its Support," Unger put forward a procedure for professional engineering societies to intervene when engineers report unfair employment practice as a result of living up to the ethics code. The proposed procedure includes "informal mediation," "investigation by a small committee," "publication of a carefully written report," and "censure of the institutions found at fault." ${ }^{.47}$ In the same article, Unger reported that in response to a CSIT request, the IEEE Board of Directors approved the filing of an amicus curiae brief in the BART case, yet "no action was taken on setting up support procedures" within IEEE itself. ${ }^{48}$

As a group, CSIT also kept pushing the IEEE administration to establish institutional means to support, even enforce, the code. During a meeting in May 1976, CSIT unanimously passed resolutions urging the IEEE United States Activities Board (USAB) to establish procedures to "aid engineers whose acts in conformity with ethical principles may have placed them in jeopardy" and to set up a committee to "receive and investigate charges of unethical behavior by IEEE members." ${ }^{49}$ CSIT also requested USAB to establish an IEEE award for "ethical behavior in the public interest under difficult circumstance." ${ }^{, 50}$

The negotiations around the proposed award for ethical behavior in the public interest highlighted the IEEE administration's ambiguous commitment to institutionally supporting ethical professional practice. Between 1973 and 1974, CSIT produced four drafts of a proposal to set up an IEEE field award for Outstanding Service in the Public Interest. The final proposal was submitted to the IEEE Awards Board, which appointed a three-person sub-committee to study the proposal. The sub-committee could not reach consensus on the merits of the award. Opponents pointed out such an award "is almost sure to involve the making of judgements in very controversial situations." "It was further suggested that "our membership, even our boards are naive in such matters and it would be better to avoid the situation entirely by only granting awards based on technical professional accomplishments. ${ }^{, 52}$

In April 1975, the IEEE Executive Committee voted to reject a permanent field award for outstanding public service. It agreed instead to consider awards in this area on a case-by-case basis. CSIT responded to this decision by unanimously nominating the three BART engineers discussed above for an Award for Public Service. One CSIT member explained that "the manner in which this motion is considered may indicate whether the case-by-case 'Award for Public Service' will be used to recognize engineers who 'acted to protect the public interest, particularly when such actions were taken despite personal risk', or whether it will be used for public relation purposes to decorate someone's lapel." ${ }^{53}$ In 1978, the three BART engineers were given the first 
IEEE CSIT Award for Outstanding Service in the Public Interest, and other such awards have followed. $^{54}$

\section{Contextualizing the Code in Engineering Ethics Education}

This paper does not attempt to provide a comprehensive history of the evolution of the IEEE Code of Ethics, nor does it trace all the institutional structures within IEEE that oversaw the implementation of the Code. Instead, through a glimpse into the history of the 1974 IEEE Code of Ethics and the debates surrounding the revision and enforcement of the Code, our analysis seeks to call attention to a few contextual matters related to such codes of ethics that govern professional engineering societies and their relationship to ethics education. Professional codes of ethics have been used widely in teaching ethics to engineering students, often by providing foundational guidance to students' ethics decision making. In many an engineering classroom, the procedure of "introducing the code; reading a case study; applying the code; identifying the ethical solution" is followed too straightforwardly. While we agree that professional codes of ethics provide an important resource for learning about engineering ethics, we contend such codes should not be facilely used in a textbook fashion to generate black-and-white answers to ethics questions. Such educational practice, we assert, actually undermines students' abilities to grapple with the intricacy and the contextual contingencies of real-world ethical quandaries. To properly reflect on the complexities, commitments, and limitations surrounding ethical decision making within the engineering profession, students would be better prepared if they could place codes of ethics in their historical, philosophical, and institutional contexts. This paper thereby promotes a more reflective approach to ethics education; we also argue that a critical look at the making of professional codes of ethics, like the one presented in this paper, provides helpful material for fostering such reflection.

The first contextual matter we call attention to is historical contingency of ethics canons. The history of the 1974 IEEE Code demonstrates that the code is not the inscription of any ultimate truth or even unanimous consensus in professional ethics, but rather is the outcome of negotiation, debate, and compromise among differently committed professionals and the institutional interests they represent. Importantly, if not surprisingly, an ethics code represents certain professional members' ethical stances more strongly than those of others. In the case of the IEEE Code, Unger's unwavering advocacy of engineers' "paramount responsibility to the public" and his belief that engineers have an ethical obligation to advance human welfare were never "codified" by IEEE. Instead, the IEEE Code advanced a set of ethical canons prioritizing engineers' responsibilities toward their employers and clients while still acknowledging responsibilities toward colleagues and the public interest. Despite this particular failure, CSIT's advocacy for the institutionalization of an IEEE Code of Ethics was successful, and the code that resulted from this advocacy ultimately reflected much of the initial work done by Unger and CSIT. Additionally, while CSIT failed to convince IEEE to institutionalize a permanent award 
for outstanding public service, their advocacy did result in the "concession" of an award to be given on a case-by-case basis. Notably, this included the very BART engineers whose actions first motivated CSIT's recognition of the need for the award. Ultimately, then, one could argue CSIT was effective in pushing IEEE to support and promulgate the idea of professional ethics for engineers. Nevertheless, some of the more socially progressive positions on professional ethics advocated by CSIT were rejected by IEEE's leadership despite CSIT's forceful, on-going activism. Lurking behind the authoritative, declarative tone of the IEEE Code are disagreements, negotiation, and institutional political processes.

The second contextual matter we call attention to is the relationship between ethics canons and situated engineering practice. Unger's and CSIT's struggles to implement the code and then to revise the code adopted by IEEE reflect the complicated role of such codes in guiding professional practice. According to any given canon, what may appear to be an obvious choice of right and wrong — as many believed was the situation in the BART case - might actually invoke a complex set of circumstances mixing divergent interests, competing notions of "the public good," institutional power relations, and a range of other contextual factors. Ethical decision making in engineering practice is more complex than simply adhering to "the Code," however important such codes may be in creating professional cultures of ethical responsibility. In fact, our analysis suggests that the cultural context of the professional organization - and the wider professional community - itself plays a role in how professional codes of ethics play out in practice. Within CSIT, there was tremendous concern over how to support engineers whose work embodies strong professional ethics yet thereby creates conflict with employers, a matter that reflects enduring structural tensions within engineering as a field of practice. The origin of these tensions lie in engineering's historic reliance on and close affinities with industrial interests, on one hand, and its commitment to the broader public interest, on the other hand. ${ }^{55}$

To an important degree, deciphering professional codes of ethics within engineering requires confronting the historic context within which such codes come into being and are promulgated. This paper has uncovered part of the historical context surrounding the formation of one professional society's code of ethics, highlighting struggles hidden by the apparent selfsufficiency of the Code's canons as promulgated today. If engineering ethics education is to provide students the conceptual tools needed for navigating ethical dilemmas in complex, always-contextualized, real-world engineering practice, codes of ethics need to play a qualified role. They should not be rejected, certainly, but neither should they be taken at face value - as an authoritative and straightforward guide to professional practice. Instead of letting the codes have the final say on ethical engineering practice, it would be more fruitful to encourage students to use them as a start for ongoing ethical inquiries. 


\section{Educational Strategies for Attending to the Context of Ethics Codes}

More reflective, contextualized approaches to using codes of ethics in engineering education certainly have been suggested and practiced in a number of cases. In addition to historical investigation of any one code, instructors might consider codes comparatively. For example, one strategy for highlighting institutions' differential commitments to ethics is for instructors to lead students in studying and comparing codes of ethics across professional societies and across national and cultural contexts. Such comparisons could even be coupled with brief historical studies of how codes were introduced within different professional or cultural contexts. In this way, universalizing claims bump up against contextual particularities, highlighting both the contingencies of all social practice and the power of shared aspirations in motivating human action. As engineering professor Patrick Little and his colleagues point out, " $[\mathrm{t}]$ he relationship between the universal aspirations of engineering ethics and their necessarily local embodiment is an opportunity for engineering practitioners, educators and students to reflect critically upon the substance of their own ethical commitments, and their reasons for holding them."56

Another strategy for fostering reflective ethical inquiry might be termed "mutual examination," by which we mean examination of the status of practice in a profession against the ethical standards enacted in its particular code, and vice versa. For example, Clause 8, which was recently added to the IEEE Code of Ethics, requires all members "to treat fairly all persons and to not engage in acts of discrimination based on race, religion, gender, disability, age, national origin, sexual orientation, gender identity, or gender expression." ${ }^{, 57}$ This clause provides rich opportunities for students to discuss the necessary structural changes to the engineering profession - in areas such as employment policies, workplace culture, college admissions, facility design, etc. - so as to live up to the code. Similarly, instructors could also encourage students to question the adequacy of a given code against the ethical concerns emerging from the profession. For example, the rapid dissemination of electronic consumer products has had a huge, exponentially increasing impact on the environment. How could a response to this problem manifest within a code of ethics? Students might deliberate on whether the IEEE Code of Ethics, for instance, should introduce a more proactive statement on engineers' specific responsibilities toward environmental stewardship. Instructors could also assign students to draft such a clause,

emphasizing that historical contingency also implies contemporary mutability of ethics codes. ${ }^{58}$

To be sure, effective ethics education requires more than appropriate pedagogies. Structural factors like accreditation requirements and other educational policy frameworks play an important role in shaping the depth of students' ethical learning. The ABET Criteria for Accrediting Engineering Programs provide one of the most important policy contexts for undergraduate engineering education in the U.S. Numerous publications address strategies to meet the eleven student outcomes required by ABET's General Criterion 3. ${ }^{59}$ Our approach would be to recommend educators create synergy across efforts seeking to meet different student 
outcomes. For example, this paper's overarching argument presumes that outcome (f), "an understanding of professional and ethical responsibility," could be more meaningfully fulfilled if its supporting educational activities are designed simultaneously to meet outcome (h), "the broad education necessary to understand the impact of engineering solutions in a global, economic, environmental, and societal context" and outcome (i), "a recognition of the need for, and an ability to engage in life-long learning." "Ultimately, we aver, ethics is the pursuit of a good life for oneself and for others, a pursuit that can only ever be meaningful in one's own life context, including one's pursuit of greater awareness (via learning) over time.

\section{Acknowledgements}

This research is partly supported by Philip L. Alger Fellowship for graduate study in engineering ethics from the Science and Technology Studies Department at Rensselaer. The authors would like to thank the staff at Cornell University Library Annex and Syracuse University Libraries for assistance to locate original sources. The authors would also like to thank anonymous reviewers for helpful feedback on prior drafts of this paper.

\section{References}

1 For a few examples, the National Society of Professional Engineers (NSPE) "Code of Ethics for Engineers" requires that engineers "must be dedicated to the protection of the public health, safety, and welfare." See http://www.nspe.org/resources/ethics/code-ethics. The Accreditation Board for Engineering and Technology (ABET) "Code of Conduct" requires all its volunteers and staff members "to disclose promptly, factors that might endanger the public." See http://www.abet.org/rules-of-procedure/.

2 Unger, S. H. 1994. Controlling Technology: Ethics and the Responsible Engineer. Second Edition. John Wiley \& Sons.

3 CSIT (Committee on Social Implications of Technology). 1978. "CSIT Honors Former BART Engineers." Technology and Society, December, No. 24.

4 Elden, W. L. "Why a State PE Board Should Enter an Amicus Curiae Brief in a 'Wrongful Discharge' Case." See http://www.nspe.org/resources/ethics/ethics-resources/other-resources/why-state-pe-board-should-enteramicus-curiae.

5 Mitcham, C. 2009. "A Historico-ethical Perspective on Engineering Education: From Use and Convenience to Policy Engagement." Engineering Studies 1:35-53.

6 Wisnioski, M. H. 2012. Engineers for Change: Competing Visions of Technology in 1960s America. Cambridge: MIT Press.

7 CSRE (Committee for Social Responsibility in Engineering). 1971. "Statement of Purpose." Spark, Vol. 1, No.1.

8 CSRE (Committee for Social Responsibility in Engineering). 1972. "EEs and Society." Spark, Vol. 2, No.1.

9 Ad hoc Committee on Social Implications of Technology. 1972. "Meeting Minutes.” June 24. 
10 CSIT (Committee on Social Implications of Technology). 1972. "Purposes." IEEE CSIT Newsletter, No. 1, December.

11 Pessah, M. A. 1972. "From the Editor." IEEE CSIT Newsletter, No. 1, December.

12 Ibid.

13 The CSIT Newsletter was published from 1972 to 1976. The newsletter was renamed Technology and Society in 1977. In 1981, the IEEE Executive Committee approved the formation of the IEEE Society on Social Implications of Technology (SSIT). SSIT's official publication became Technology and Society Magazine, which is still published today. This paper mainly draws from the CSIT Newsletter (1972 to 1976).

14 Unger currently chairs the IEEE SSIT Standing Committee on Ethics. See http://ieeessit.org/2015/01/01/2015ssit-officers-board-chairs-and-liasons/.

15 Unger, S. H. 1973. “The BART Case: Ethics and the Employed Engineer.” IEEE CSIT Newsletter, No. 4, September.

16 Ibid.

17 Ibid.

18 Unger, S. H. 1994. Op. cit.

19 Unger, S. H. 1973. "A Proposal to Support the Ethical Engineer.” IEEE CSIT Newsletter, No. 5, December.

20 Unger, S. H. 1973. "Codes of Engineering Ethics.” IEEE CSIT Newsletter, No. 5, December.

21 Unger, S. H. 1973. "A Proposal to Support the Ethical Engineer.” Op. cit.

22 Mitcham, C. 2009. Op. cit.

23 Elden, W. L. 1974. "The Dilemma of the Professional Engineer Employed in Industry.” IEEE CSIT Newsletter, No. 6, March. Elden is another IEEE member who worked actively to promote professionalism and ethical practice. "When his pro-active professional activities became unacceptable to the Management of Martin Marietta, with a resulting unrestrained pressure being applied upon him to quit advocating them, he 'resigned his position under coercion' in August 1974 from Martin Marietta." See http://www.onlineethics.org/Connections/Community/WElden.aspx.

24 Anderson, R. W. 1974. "Ethical Professionals without Support: A Case in Point." IEEE CSIT Newsletter, No. 7, June.

25 "IEEE Code of Ethics." Spectrum. February 1975.

26 The Engineers' Council for Professional Development (ECPD) was founded in 1932 to address issues related to licensing professional engineers. It contained a number of constituent engineering societies, including AIEE (and later IEEE). See Layton, E. T. 1986. The Revolt of the Engineers: Social Responsibility and the American Engineering Profession. Baltimore and London: The Johns Hopkins University Press. In 1944, an ECPD joint committee produced "Canons of Ethics for Engineers" and recommended them to its constituent societies for adoption. See Jackson, D. C. 1944. “The ECPD Proposed Canons of Ethics.” Electrical Engineering, Vol. 63, No. 12. The ECPD "Canons" was revised in 1963, 1974, and 1977. See Mitcham, C. 2009. Op. cit.

27 "IEEE Code of Ethics." 1975. Op cit.

28 Unger, S. H. 1973. "Codes of Engineering Ethics.” Op. cit.

29 "IEEE Code of Ethics." 1975. Op cit.

30 "IEEE Code of Ethics." 1975. Op cit.

31 Unger, S. H. 1973. "Codes of Engineering Ethics.” Op. cit.

32 Unger, S. H. 1973. "Codes of Engineering Ethics.” Op. cit.

33 It is less clear whether Canon 3 primarily addresses the social impacts of engineering projects. The readers might note a similar canon is placed under Article III, the article that discusses engineers' responsibilities to their employers and clients, in the IEEE Code of Ethics for Engineers. 
34 Unger, S. H. 1973. "Codes of Engineering Ethics.” Op. cit.

35 "IEEE Code of Ethics." 1975. Op cit.

36 Unger, S. H. 1973. "Codes of Engineering Ethics.” Op. cit.

37 Ibid.

38 Unger, S. H. 1976. "Ethics for Engineers: A Code and Its Support." IEEE CSIT Newsletter, No. 13, March.

39 Ibid.

40 Ibid.

41 Ibid.

42 Ibid.

43 Ibid.

44 As a growing number of people who were not engineers joined IEEE, the Code was revised in 1979 to recognize this change in membership. The main change in the code was replacing "engineers" with "engineers, scientists and technologists." See Pugh. E. W. 2009. "Creating the IEEE Code of Ethics." IEEE Conference on the History of Technical Societies.

45 Unger, S. H. 1973. "Codes of Engineering Ethics.” Op. cit.

46 Unger, S. H. 1973. "Ethics for Engineers: A Code and Its Support.” Op. cit.

47 Ibid.

48 Ibid.

49 CSIT (Committee on Social Implications of Technology). 1976. "Ethics Code Support and Endorsement." IEEE CSIT Newsletter, No. 14, July.

50 Ibid.

51 Kaufman, J. S. 1976. “An IEEE Award for Outstanding Service in the Public Interest.” IEEE CSIT Newsletter, No. 14, July.

52 Ibid.

53 Ibid.

54 CSIT (Committee on Social Implications of Technology). 1978. "CSIT Honors Former BART Engineers.” Op. cit.

55 Layton, E. T. 1986. Op. cit. See also Noble, D. F. 1979. America by Design: Science, Technology, and the Rise of Corporate Capitalism. Oxford University Press.

56 Little, P., Barney, D., and Hink, R. 2008. "Living Up to the Code: Engineering as Political Judgment." International Journal of Engineering Education, Vol. 24, No. 2, 314-27.

57 IEEE. 2015. "Code of Ethics.” Accessed from: http://www.ieee.org/about/corporate/governance/p7-8.html.

58 Nieusma, D. Forthcoming. "Analyzing Context by Design: Engineering Education Reform via Social-Technical Integration.” In Christensen, S. H.; Didier, C.; Jamison, A.; Meganck, M.; Mitcham, C.; Newberry, B. (eds.), International Perspectives on Engineering Education: Engineering Education and Practice in Context. Volume I. Springer Science + Business Media B.V.

59 Engineering Accreditation Commission, ABET. 2013. Criteria for Accrediting Engineering Programs: Effective for Review during the 2014-2015 Accreditation Cycle. ABET.

60 Ibid. 